INTERNATIONAL JOURNAL OF MULTIDisciplinARY RESEARCH AND ANALYSis

ISSN(print): 2643-9840, ISSN(online): 2643-9875

Volume 04 Issue 10 October 2021

DOI: 10.47191/ijmra/v4-i10-04, Impact Factor: 6.072

Page No.- $1370-1376$

\title{
Theme of the Article: The Determinants of the Demand for Tobacco in Togo
}

\section{Makiliwè Barcola}

\begin{abstract}
This paper analyzes the relationship between the demand for tobacco, its price and the economic factors that may influence it. The objective is to understand the response of consumers to an increase in tobacco prices. The price increase is assumed to be caused by the effect of increasing tobacco taxes, which is a major tobacco control policy. This paper also analyzes the reaction of smokers to an increase in the prices of other goods in the economy. To achieve this objective, we estimate the elasticities of these factors through the tobacco demand models proposed in the literature. The price of tobacco, consumer income per capita, the price of goods such as food and health care, and the strengthening of anti-smoking laws are among the variables used to estimate the demand equations for tobacco. The results of the estimations indicate first that the demand for tobacco is highly elastic with respect to its price; the price elasticity is estimated at -1.368 . Tobacco demand is also sensitive to consumer income and the strengthening of anti-smoking laws. In contrast, changes in the prices of other non-addictive goods in the economy, such as food, have no influence on the demand for tobacco products. This means that when the price of other products increases, smokers are likely to reduce the quantity of these products consumed in order to maintain their level of tobacco consumption.
\end{abstract}

KEY WORDS: Tobacco, Elasticity and Demand.

\section{INTRODUCTION}

Tobacco use is the major preventable cause of death from Non-Communicable Diseases according to the World Health Organization (WHO, 2019). The same WHO report states that tobacco use now kills nearly half of those who use it, or more than eight million deaths per year. These deaths do not only concern tobacco smokers but also non-smokers who are, in one or other way, exposed to smoke. The situation is much more concerning when we realize that nearly 860 million smokers live in low-income countries where health care remains a major challenge, making tobacco use the largest public health epidemic in Sub-Saharan Africa.

Togo, a developing country in Sub-Saharan Africa, which is the setting for our study, has an estimated smoking prevalence of $10.4 \%$ for adult men and $0.2 \%$ for adult women. The harmful effects of smoking on the health and economy of poor countries are often brandished by advocates of public health theory, according to whom it is more than necessary for public authorities to intervene to fight against this scourge and to protect smokers from themselves. The question of the legitimacy of such a desired and requested intervention arises when we know that it is possible that the smoker knows the risks linked to his consumption and assumes them, making him a rational consumer.

This argument, which opposes state intervention to fight or reduce tobacco consumption, is used by the tobacco industry and is even based on economic theories. In this sense, the theory of the rationality of the tobacco consumer (Becker et al., 1994) poses the hypothesis that individuals who use tobacco make perfect predictions and take into account their future consumption by making choices in the present. They are fully aware of the future consequences of their current choices and incorporate these consequences into the choices they make today. This being the case, any intervention aimed at protecting the consumer from himself is not necessary.

In order to avoid accusations of paternalism, the public health argument has abandoned the smoker's welfare argument that tobacco control policies should protect smokers from themselves. If it is not totally proven that smokers are non-rational, it is obvious that smoking has consequences on non-smokers and, given this observation, any state intervention aiming at minimizing 


\section{Theme of the Article: The Determinants of the Demand for Tobacco in Togo}

these costs induced by smoking cannot be rejected. Even if the regulator is not entitled to dictate consumer behavior, it can at least try to make the consumer pay for the costs he or she induces in others. Most public policies to control tobacco consumption rely on three (3) tools, summarizing the six (6) MPOWER ${ }^{1}$ control measures proposed by the WHO in 2008, namely: information dissemination, taxation and bans. A combination of tax increases and advertising bans, information campaigns on the effects of tobacco use, and restrictions on tobacco use in public places should result in a reduction in tobacco use, a reduction in passive tobacco use, and an increase in government revenues from tobacco taxation that can be used to treat victims of tobacco-related diseases.

Under normal circumstances, there is an inverse relationship between the demand for tobacco and the increase in price induced mainly by the tax increase: as the cigarette price rises, the demand for it falls. Income elasticity, on the other hand, reflects the ability of the population to purchase the product as a function of changes in per capita income. The usual relationship is in the right direction, with the ability to purchase, or demand, increasing as per capita income increases. Anti-smoking advertisements, restrictions, and higher prices for other goods in the economy should reduce the demand for tobacco. Although many previous studies agree on these effects on tobacco demand, many other studies have had to point to their limitations; this has raised new questions.

Estimating these parameters that influence the demand for tobacco products would be useful in that it would allow us to know precisely the effect of tax and price increases on tobacco demand, as well as the effect of tobacco control measures, which is the main objective of this study. This paper aims to achieve this objective by conducting an empirical analysis of the demand for cigarettes in Togo during the period 2010-2017 to estimate the income and price elasticities that are economic factors that should act on the demand for tobacco products and finally the effect of restrictions on the demand for cigarettes.

\section{BACKGROUND OF THE STUDY}

Our study focuses on Togo, which is an exclusively tobacco importing country with almost no local production and an estimated smoking prevalence in 2019 of $10.4 \%$ for adult men and $0.2 \%$ for adult women.

Data on tobacco imports ${ }^{2}$ from the database of the Office Togolaise des Recettes (OTR) show that in value terms, imported tobacco products have increased from 6941 million CFA francs or 1471.3 tons of cigarettes in 2010 to 8192 million CFA francs in 2013, equivalent to 2517.8 tons. This situation suggests that the timid decline in smoking prevalence is coupled with either an increase in the quantity of tobacco consumed by tobacco users or an increase in the number of consumers, as the population grew between 2010 and 2013.

In any case, cigarette consumption remains a scourge to be fought in a country where more than half of the population lives below the poverty line and where access to quality health care remains a major challenge. In 2017 this prevalence estimated with the quantity of imported cigarettes (1333.2 tons) has experienced a slight decrease compared to 2010.

\section{Figure 1: Price and volume trends of tobacco products in Togo}

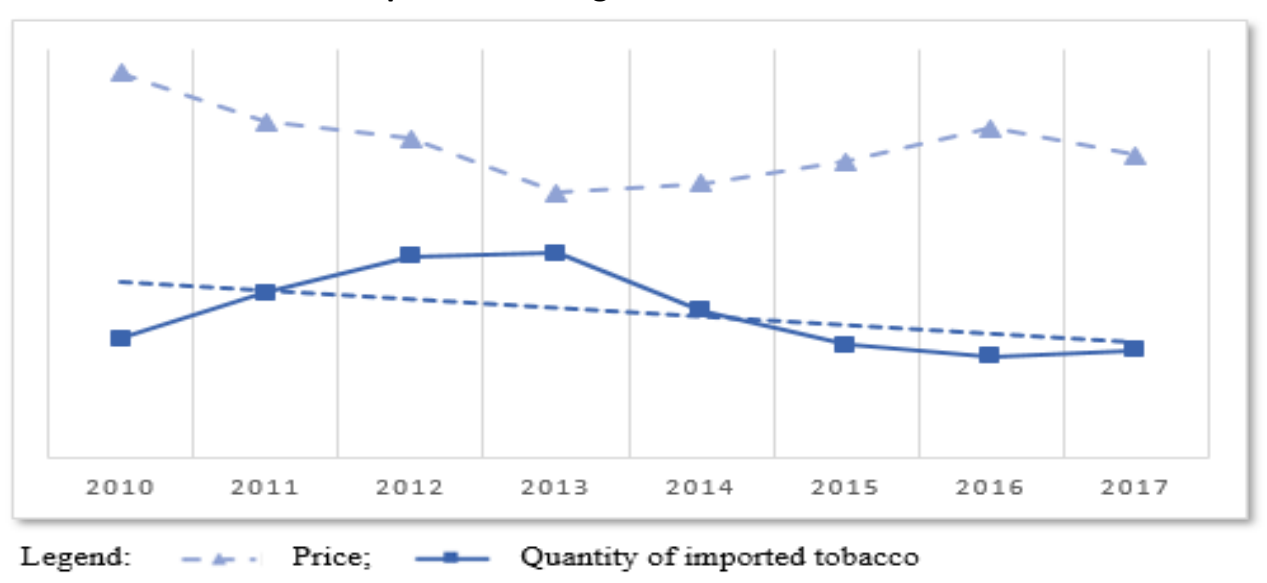

Source: Author, based on data from the OTR

\footnotetext{
${ }^{1}$ These measures are: Monitor tobacco use and prevention policies, Protect the public from tobacco smoke, Offer assistance to those who want to quit, Warn about the dangers of tobacco use, Enforce the ban on tobacco advertising, promotion and sponsorship, and Raise taxes on tobacco.

${ }^{2}$ Most tobacco imports are for consumption, as Togo doesn't export tobacco at all. This is why in our work, we will assimilate imported tobacco to consumed tobacco.
} 


\section{Theme of the Article: The Determinants of the Demand for Tobacco in Togo}

\section{EMPIRICAL LITERATURE REVIEW ON TOBACCO DEMAND}

Several studies have sought to analyze the demand for tobacco products, and the first ones focused on developed countries before later considering developing countries. Studies devoted to Sub-Saharan Africa began in 1994 (Reekie, 1994; Walbeek, 1996).

Particular emphasis is placed on studying the demand for tobacco products and the effect of changes in tobacco prices, income, and other determinants on tobacco demand, consumption, or initiation. The main reason for studying the demand for tobacco is to gain sufficient knowledge about how to efficiently influence tobacco consumption. In addition to the traditional ${ }^{3}$ variables considered in the analysis of tobacco demand; socio-demographic variables have been included in new studies that seek to assess the influence of these variables on the consumption of tobacco products. Among tobacco products, cigarettes have been the most widely used in previous studies, on which we will focus.

Indeed, the majority of studies are conclusive and convergent on the link that can exist between the demand for tobacco and its price. Chaloupka et al (2011), on an analysis of several studies, conclude that: increasing tobacco excise taxes and tobacco prices is effective and reduces overall tobacco consumption and smoking prevalence. It therefore has an impact on improving public health, including preventing smoking initiation and uptake by youth and encouraging cessation among former users.

While it is clear that the coefficient of the price elasticity of demand for cigarettes is negative, making cigarettes a normal good, the discrepancy becomes much more remarkable when it comes to evaluating this coefficient and classifying tobacco as an inelastic or elastic good. In this sense, the countries of the South differed from the countries of the North in the impact that a change in the price of cigarettes can have on the quantity of tobacco demanded. The effect is smaller in the northern countries (the price elasticities of cigarettes were between -0.30 and $-0.50^{4}$ ).

As for the countries of the South, more precisely in Africa, the majority of the studies done on tobacco demand and almost all the pioneering studies have focused on South Africa. These studies (Reekie, 1994; Saloojee, 1995; Walbeek, 1996; Economics of Tobacco Control Project, 1998; Walbeek, 2005; Boshoff, 2008) show that the price elasticity is between -0.16 and -1.52 while the income elasticity is between 0.37 and 1.70 , making tobacco a normal but elastic good.

Recently, many studies have focused on other African countries and attempt to determine the price and income elasticities of demand as well. Ho et al, (2017) examine the effects of price increases on cigarette consumption, tobacco tax revenues, and reductions in smoking mortality in 36 African countries. Using panel data, they applied fixed-effects and random-effects regression methods to estimate the elasticity of cigarette prices and simulate the effects of their fluctuations. They find that cigarette price elasticity was higher for low-income countries and significantly lower for other African economies. The simulation shows that with an average annual increase in cigarette prices of $7.38 \%$, average annual cigarette consumption would decrease by $3.84 \%$ and average annual tobacco tax revenues would increase by $19.39 \%$.

With advances in work on tobacco demand models and new estimation methods, a difference is made between short- and longterm elasticities. In France, pioneering work in this direction was done by Anguis and Dubeaux (1997). Using the Vector Error Correction Model (VECM) on quarterly data describing tobacco consumption, they showed that in France, the price elasticity of demand was -0.3 in the long run and -0.5 in the short run. In other words, following a $10 \%$ increase in the price of tobacco, consumption falls by $5 \%$ in the short run (the following quarter) and by $3 \%$ in the long run (the following years). Using the same methodological framework but on annual data (cigarette sales in millions of units) from 1980 to 2000, Godefroy (2003) finds a long-run elasticity of -0.4 , which is not far from that found above.

Wilkins et al (2004) recommend that the analysis of demand for tobacco products focus on retail, rather than wholesale, tobacco. This recommendation is motivated by the fact that tobacco company profits are totally influenced by retail sales. This illustrates very well the direction taken by many studies that have sought to measure retail demand for tobacco products through the use of individual data.

Other authors have tried to measure the effect of other factors, such as income and socioeconomic factors, on tobacco demand. Farrelly et al (2001) worked on states, considering socioeconomic variables and response to a tobacco price increase. They find that women, adults at or below middle income, youth who are self-sufficient, African-Americans, and Hispanics are most sensitive to cigarette price increases. For example, adults with incomes at or below the mean are four times more sensitive to price changes

\footnotetext{
${ }^{3}$ These are: the price of tobacco consumption, consumer income and the price of other goods.

${ }^{4}$ Chaloupka et Warner (2000), and International Agency for Research on Cancer (Centre international de recherche sur le cancerCIRC), 2011
} 


\section{Theme of the Article: The Determinants of the Demand for Tobacco in Togo}

than those with incomes above the mean. Van (2005) studied South Africa and found that bans on tobacco advertising and smoking in public places and workplaces deformalize and discourage smoking and are likely to make other tobacco control interventions more effective.

\section{METHODOLOGY AND RESULTS OF THE ESTIMATION OF DEMAND MODELS}

\subsection{Choice of models}

The models used to analyze the demand for tobacco products, using aggregate time series data, often fall into two categories: socalled conventional models and addiction demand models. The difference between the two types of models lies in the consideration of the type of good that is tobacco and the link between the past and present behaviors of tobacco consumers.

Proponents of the conventional demand model, which is a static model that treats tobacco like other goods (ignores the fact that tobacco is an addictive good), just examine the impact of explanatory variables on the demand for tobacco goods, all at the same time. The amount of tobacco consumed today is unrelated to the amount consumed in the future or even in the past. Thus, the analysis of tobacco consumer behavior does not take into account past consumption patterns. Used by Winston (1980), Bishop and Yoo (1985), Chaloupka and Saffer (1992), Barnett et al (1995), Haughton (1998), Karingi et al (2001) and Martinez et al (2015), it has been able to estimate changes in tobacco consumption as a result of changes in taxes that affect tobacco consumption. The model known as myopic dependence (Mullahy, 1985; Baltagi et al., 1986) assumes that beyond the variables considered in the conventional demand model, tobacco demand depends on a stock of habits representing the depreciated sum of all past consumption. Past tobacco consumption must be taken into account when modeling present consumption.

In our paper, both models will be estimated, using the Log-Log specification by incorporating the variables to be considered in the analysis.

We will then get:

Model 1: $\ln Q_{t}=b_{0}+b_{1} \ln P_{t}+b_{2} \ln I P A_{t}+b_{3} \ln I P S_{t}+b_{4} \ln R_{t}+b_{5} D m_{t}+\varepsilon_{t}$

Model 2: $\ln Q_{t}=b_{0}+b_{1} \ln P_{t}+b_{2} \ln I P A_{t}+b_{3} \ln I P S_{t}+b_{4} \ln R_{t}+b_{5} D m_{t}+b_{6} \ln Q_{t-1}+\varepsilon_{t}$

, where equation 1 represents the Conventional Model and equation 2 the Myopic Model.

$\ln Q_{t}$ And $\ln Q_{t-1}$ represent the logarithm of the total quantity of tobacco consumed in period $\mathrm{t}$ and the past period (t-1), respectively.

$\ln P_{t}$ is the logarithm of the average price of tobacco in period $\mathrm{t}$.

$\ln R_{t}$ is the logarithm of the per capita income of tobacco users in period t.

$\ln I P S_{t}$ et $\ln I P A_{t}$ represent respectively the logarithm of the consumption prices of other goods, more precisely here of health and food goods in period $t$.

$D m_{t}$ is a binary dummy variable that takes the values 0 and 1 , and that represents the implementation of an anti-smoking law that would probably affect the demand for tobacco in period $t$.

$b_{0}, b_{1}, b_{2}, b_{3}, b_{4}, b_{5}, b_{6}$ are the coefficients to be estimated.

$b_{1}$ et $b_{4}$ represent the price and income elasticities of demand for tobacco goods.

\subsection{Outcome Of The Estimations And Interpretation}

The results ${ }^{5}$ of the validation tests allow us to estimate the models by the Ordinary Least Squares method. We estimate our two models by the OLS method and we discuss some results from this estimation.

5 These results are reported in Table 2 in the Appendix 


\section{Theme of the Article: The Determinants of the Demand for Tobacco in Togo}

The table below presents the results of the OLS estimations of the models. The estimation of the conventional model (Model 1) indicates that the price of tobacco, per capita income, and the dummy variable representing the strengthening of tobacco laws are significant and have effects on the demand for tobacco. While the price of other goods as well as past tobacco consumption have no influence on the quantity of tobacco demanded.

Indeed, the results indicate that the price elasticity coefficient of tobacco is -1.368 : tobacco is a highly elastic good in Togo. These estimated coefficients for model 1 are not far from the estimated coefficients for model 2 . Thus, a $10 \%$ increase in the price of tobacco reduces (more than proportionally) the quantity of tobacco consumed by $13.68 \%$. This result seems correct and only supports the first hypothesis of this paper. We were able to point out in our literature review that developing countries seem to be more sensitive to changes in tobacco prices Ho et al, (2017). Tobacco control policies that increase tobacco prices will tend to decrease the amount consumed.

Table 1: Results of estimations

\begin{tabular}{|l|c|c|}
\hline & $(1)$ & $(2)$ \\
\hline VARIABLES & Model 1 & Model 2 \\
\hline Tobacco price & $-1.368^{* * *}$ & $-1.381^{* * *}$ \\
\hline Income & $(0.274)$ & $(0.277)$ \\
\hline Health Goods Prices & $-0.929^{* * *}$ & $(0.282)$ \\
\hline Food Goods Prices & $(0.260)$ & 0.632 \\
\hline Quantity purchased at period t-1 & 0.817 & $(2.568)$ \\
\hline & $(2.549)$ & 1.428 \\
\hline Tobacco control & 1.259 & $(1.469)$ \\
\hline & $(1.446)$ & -0.0905 \\
\hline
\end{tabular}

Standard errors in parentheses; $* * * p<0.01, * * p<0.05, * p<0.1$

Source: Author

As the estimation methods did not allow us to differentiate the participation elasticity (the price sensitivity that translates into quitting or not starting smoking) from the conditional demand elasticity (the price sensitivity that translates into a decrease in consumption of individuals who continue to smoke), It would be difficult for us to say clearly whether the small variation in the quantity consumed between 2013 and 2017 is attributable to the small decrease in the quantities smoked by tobacco users or to the growth in the number of users following the initiation of new users to smoking.

The conventional demand model does not allow us to determine long-run and short-run elasticities. To do so, we must switch from the conventional model to the myopic model for which the OLS estimation method remains valid.

Doucouré (2014) suggests that with an autoregressive model, we can determine the long-run elasticities by a small calculation ${ }^{6}$. We consider model (2) estimated by least squares. We find that the estimated coefficient of past consumption is negative (-0.09)

${ }^{6}$ Doucoure (2014) considers the following autoregressive model:

$\log \left(Y_{t}\right)=b \log \left(Y_{t-1}\right)+a_{0}+a_{1} \log \left(X_{1 t}\right)+a_{2} \log \left(X_{2 t}\right)+\ldots+a_{k} \log \left(X_{k t}\right)+\varepsilon_{t}$ 


\section{Theme of the Article: The Determinants of the Demand for Tobacco in Togo}

but not significant, so it is in fact considered null. This means that, ceteris paribus, our short-run elasticity is approximated by the long-run coefficient.

Concerning the income elasticity, it indicates a negative value, significantly higher than -1: (-0.09), which is contrary to many of the conclusions of several studies done in both Southern and Northern countries (Wasserman et al., 1991, Keeler et al., 1993, Yurekli and Zhang, 2000). The negative income elasticity indicates that tobacco is rather an inferior good in our context. This result can be explained by the fact that the majority of cigarettes sold in Togo are cheap cigarettes and as income increases, these cigarettes are abandoned in favor of other products. Also, the increase in income, which is synonymous with more employment, may explain the decrease in consumption, given that the busier one is, the less one smokes in countries where smoking is prohibited everywhere.

Moreover, the elasticity coefficients associated with the other goods consumed by the smoker are not significant and suggest that tobacco consumers do not change their consumption in favor of other goods. On the contrary, he is ready to maintain the quantity of tobacco to be consumed, even if the prices of other goods have increased. Therefore, the other (non-addictive) goods are neither substitutes nor complements to the addictive goods.

Finally, we consider the effect of stronger smoke-free laws on tobacco demand. Contrary to some studies (Krugman, 1999) which think that a reinforcement of anti-smoking laws would not necessarily have an impact on smoking initiation or on smokers, our estimates reveal that it has a real negative impact on the demand for tobacco.

\section{CONCLUSION}

This paper allowed us to evaluate, on the one hand, the effects of tobacco control measures that result in an increase in the price of tobacco on the quantity demanded of tobacco. Then, we measured the reaction of smokers to an increase in the price of other goods in the economy, income and the strengthening of anti-smoking laws. These objectives led us to analyze the demand for tobacco and the factors that could influence it, in order to better understand the Togolese environment and to better propose tobacco control policies.

The main results of our study are as follows

(1) The estimated price elasticity coefficient of tobacco (-1.368) making tobacco an elastic good in the Togolese context. Although sensitive to price, the quantity of tobacco consumed did not decrease considerably over the study period, probably due to the entry of new smokers into the market, most of whom are assumed to be young.

(2) Tobacco is a cheap good and there is evidence that the majority of consumers are those with the lowest incomes because an increase in average income is coupled with a decrease in demand for tobacco.

(3) Food and health goods are not substitutes or complements for tobacco. An increase or decrease in their price has no effect on the demand for tobacco. Tobacco consumers will seek to maintain their level of tobacco consumption even with increases in the prices of other goods.

(3) Laws that strengthen tobacco control tend to decrease tobacco consumption.

The recommendations made on the basis of the results emphasize a joint policy of permanent taxation and strengthening of tobacco control laws targeted at young people.

A limitation of this paper, which may be the subject of further study, is its inability to differentiate between the participation elasticity and the conditional elasticity of tobacco product consumption.

\section{BIBLIOGRAPHIC REFERENCE}

1) Atkinson, A. B., \&Skegg, J. L. (1973). Anti-smoking publicity and the demand for tobacco in the UK. The Manchester School, 41(3), 265-282.

2) Becker, G. S., \& Murphy, K. (1999). A theory of rational addiction. Journal of Political Economy.

$a_{1}, a_{2}, \ldots, a_{k}$ are the short-term coefficients, while

$\frac{a_{1}}{1-b}, \frac{a_{2}}{1-b}, \ldots, \frac{a_{k}}{1-b}$ Are the long-term coefficients. 


\section{Theme of the Article: The Determinants of the Demand for Tobacco in Togo}

3) Becker, G. S., Grossman, M., \& Murphy, K. M. (1991). Rational addiction and the effect of price on consumption. The American Economic Review, 81(2), 237-241.

4) Becker, G. S., \& Murphy, K. M. (1988). A theory of rational addiction. Journal of political Economy, 96(4), 675-700.

5) Chelwa, G., \& van Walbeek, C. (2019). Does cigarette demand respond to price increases in Uganda? Price elasticity estimates using the Uganda National Panel Survey and Deaton's method. BMJ open, 9(3), e026150.

6) Chaloupka, F. J., Straif, K., \& Leon, M. E. (2011). Effectiveness of tax and price policies in tobacco control. Tobacco Control, 20(3), 235-238.

7) Chaloupka, F. J., \& Warner, K. E. (2000). The economics of smoking. Handbook of health economics, 1, 1539-1627.

8) Ciecierski, Christina U.; Chaloupka, Frank Joseph; Yurekli, AydaAysun; De Beyer, Joy Antoinette. 2001. Data for economic analysis (English). World Bank economics of tobacco toolkit; no. 2. tobacco data. Washington, D.C. : World Bank Group.

9) Dupilet, C., Grignon, M., \&Pierrard, B. (2002). Modèleséconomiques et politiques de luttecontre le tabagisme. CREDES.

10) Farrelly, M., Bray, J., Pechacek, T., \&Woollery, T. (2001). Response by Adults to Increases in Cigarette Prices by Sociodemographic Characteristics. Southern Economic Journal, 68(1), 156-165. doi:10.2307/1061518

11) Kopp, P. (2006) Analyseéconomique du comportement du fumeur, Centre d’Economie de la Sorbonne C.E.S., Université de Panthéon-Sorbonne, Paris.

12) Krugman, D. M., Fox, R. J., Fletcher, J. E., Fischer, P. M., \& Rojas, T. H. (1994). Do adolescents attend to warnings in cigarette advertising? An eye-tracking approach. Journal of advertising research, 34(6), 39-52.

13) Laporte, A., Dass, A. R., \& Ferguson, B. S. (2017). Is the Rational Addiction model inherently impossible to estimate?. Journal of health economics, 54, 161-175.

14) Martinez, E., Mejia, R., \& Pérez-Stable, E. J. (2015). An empirical analysis of cigarette demand in Argentina. Tobacco control, 24(1), 89-93.

15) Mehrotra, R., Yadav, A., Sinha, D. N., Parascandola, M., John, R. M., Ayo-Yusuf, O., ... \& Siddiqi, K. (2019). Smokeless tobacco control in 180 countries across the globe: call to action for full implementation of WHO FCTC measures. The Lancet Oncology, 20(4), e208-e217.

16) Peto, J. (1974). Price and consumption of cigarettes: a case for intervention?. Journal of Epidemiology \& Community Health, 28(4), 241-245.

17) Showalter, M. H. (1999). Firm behavior in a market with addiction: The case of cigarettes. Journal of health economics, $18(4), 409-427$.

18) Stigler, G. J., \& Becker, G. S. (1977). De gustibus non estdisputandum. The american economic review, 67(2), 76-90.

19) Wangen, K. R. (2004). Some fundamental problems in Becker, Grossman and Murphy's implementation of rational addiction theory (No. 375). Discussion Papers.

20) Wilkins, N., Yurekli, A., \& Hu, T. W. (2004). Economic analysis of tobacco demand. Economics of Tobacco Toolkit, 80576.

\section{APPENDIX}

Table 2: Results of the validation tests

\begin{tabular}{|c|c|c|c|}
\hline Tests & Tests Null hypothesis (H0) & Prob & Decision \\
\hline (1) Fisher's global significance test & $\begin{array}{l}\text { H0: The coefficients of the model are not } \\
\text { significantly different from zero (0) }\end{array}$ & 0.000 & $\mathrm{H} 1$ \\
\hline (2) Test of endogeneity & $\begin{array}{l}\text { H0: The variable is endogenous } \\
\text { (Instrument: Taxes) }\end{array}$ & 0.000 & $\mathrm{H} 1$ \\
\hline $\begin{array}{l}\text { (3) Skewness and Kurtosis test of residuals } \\
\text { normality }\end{array}$ & H0: Residues follow a normal distribution & 0.2502 & $\mathrm{HO}$ \\
\hline $\begin{array}{l}\text { (4) Breusch-Pagan heteroscedasticity test of the } \\
\text { errors }\end{array}$ & HO: The errors are homoscedastic & 0.2196 & $\mathrm{HO}$ \\
\hline (5) ARCH conditional heteroscedasticity test & H0: The errors are homoscedastic & 0.7438 & $\mathrm{HO}$ \\
\hline $\begin{array}{l}\text { (6)Breusch-Godfrey 1st order autocorrelation test } \\
\text { of LM errors }\end{array}$ & H0: The errors are not autocorrelated & 0.2096 & $\mathrm{HO}$ \\
\hline (7) Durbin-Watson alternative autocorrelation test & HO: The errors are not autocorrelated & 0.2289 & $\mathrm{HO}$ \\
\hline (8) Ramsey specification test & HO: The model is well specified & 0.000 & $\mathrm{HO}$ \\
\hline
\end{tabular}

NB: $\mathrm{H} 1$ is the alternative hypothesis

Source: Author 